\title{
Psycho social needs of the care givers of the children with disabilities - a qualitative study in a rural community of Karnataka.
}

\author{
Rathna kumari $\mathrm{S}^{1}$ Dr. Mary Venus Joseph ${ }^{2}$ Dr. Sulekha $\mathrm{T}^{3}$ Chandrasekhar $\mathrm{D}^{4}$ \\ ${ }^{I}$ (Social Scientist Department of Community Health St. John's Medical College, Bangalore, Karnataka India). \\ 2. (Dean and Administrator Rajagiri School of Social Work, Kalamassery, Kochi Kerala, India). \\ ${ }^{3}$ (Associate Professor, Department of Community Health, St. John's Medical College Bangalore, Karnataka \\ India) \\ ${ }^{4}$ (Medico Social Worker Department of Community Health St. John's Medical College Bangalore, Karnataka, \\ India)
}

\begin{abstract}
Care givers play a central role in the lives of the children with disabilities. Their well being is essentially linked to that of their children. The socio cultural practices among the people in rural and urban community vary. Using a qualitative research method this was an attempt was to find the psychosocial needs of the caregivers while caring their children with disabilities in a rural community. The need for the study was to develop a psycho social intervention programme for the care givers of the children with disabilities to improve their quality of life based on their needs. Focus group discussions and In-depth interviews were conducted with 25 mothers and 2 grand mothers of the children with disabilities. The time duration of the study was two months. The findings of this study are: Need of emotional support, to reduce the stigma and ostracism towards disable individuals, need for financial support, reducing family burden and need for improving perceived social support to the care givers.
\end{abstract}

Key words: Caregivers, Needs, Disability, Qualitative

\section{Introduction}

The birth of a baby in a family usually creates great excitement and expectations. It brings happiness and feeling of fulfillment among parents. Before the birth of a child, parents have their own hopes to see the future of the new comer to their family. This may become muted with the birth of a baby with special needs. Having a child with special needs born into a family and grow into adulthood is one of the most difficult and stressful experiences to a family Parental reactions to realize that their child is exceptional usually include shock, depression, guilt, anger, sadness, loss of emotions and anxiety. Some of parents perceive the child with special need may feel shame, social rejection or embarrassment. The family may feel social isolation and may refuse to attend social gatherings, invite people to home or to visit others. Parents with disabled child take time to accept the fact of the child's functional disabilities. This may vary from parent to parent [1]. Once they accept their situation in the society, the level of psycho social problems will be low. These problems can have direct impact on the care of the child.

Disability is any restriction or lack (resulting from an impairment) of ability to perform an activity in the manner or within the range considered normal for a human being (WHO 1976) [2]. Different prevalence rates for disability are available in India. National Sample Survey Organization estimated that the number of persons with disabilities in India is 1.8\% (49-90 million) of the Indian population (NSSO 2002), $75 \%$ of them live in rural areas[3]. Disabilities continue to be an expanding life condition of an individual throughout the world. The proportion of children and families affected with disabilities has continued to be a significant public health problem. With the availability of advanced technology identifying and intervening with person affected with disabilities, has shifted from one condition to the other. As a result, there are numbers of children surviving into adolescence and adulthood[4]. Shifts in the pattern of the persons with different disabilities require care givers in broader prospective to recognize and address the needs of this growing population.

Care givers play a central role in the lives of the children with disabilities. Their well being is essentially linked to that of their children. Care givers are the instrumental partners who take an active role influencing the nature and direction in to the care of their child[5]. Depending on the severity of the child's disability, there are risks of psychosocial problems among the care givers. The majority of parents of the children with disabilities have lack of social support; financial problems and marital disharmony. They also blame themselves. They suffer from social stigma, family burden, lack of support to receive care to improve the 
quality of life child as well as self care. They are typically confronted by daily life stress, financial consequences, and family disruption. These important contextual issues need a closer investigation.

The present study aims to develop an understanding of the current psychosocial needs, experiences, and perceptions of current life situations among the parents of the children with disabilities using an individual indepth interview and focus group discussion methods. Information gained from this study will be used to develop a training module on family centred psycho social intervention for the care givers of the children with disabilities to improve their quality of life as well as their children.

\section{Methodology}

Objectives:

1. To identify the psycho social needs of the care givers of the children with disabilities by a qualitative assessment.

2. To identify unique situations and concerns experienced by the caregivers of the children with disabilities in regular care giving process.

A qualitative study using In-depth interviews and focus group discussions (FGDs) was done. Parents and care givers of children with disabilities were identified from records held by the outpatient disability clinic at Community Health Training Centre Mugalur village, Anekal Taluk, Bangalore District. Randomly selected samples of 27 potential participants were met in their household to get their consent and were invited to take part in the study. A series of two focus groups and 12 in-depth interviews were held twenty seven participants (100\% female). One focus group discussion was conducted at the Community Health Training Centre with seven participants and another at a Community Hall in one of the villages of respondents consisting of eight participants. Sitting arrangement was made in a circle followed during the focus group discussions. Twelve indepth interviews were done till investigator felt the repeation in the content of the information. Each of which was conducted in a separate room to avoid any disturbances. Each discussion began with an introduction by the researchers, followed by introduction from all the participants. The moderator used an interview guide which was used to direct discussions. Discussions were lasted to 1 to 2 hours in each group. The small numbers of participants at each focus group discussions and many in in-depth interviews data was generated using these two qualitative methods. The in-depth and focus group discussion were facilitated by a team, comprising one moderator (MO), one reporter (RP). After each session, the moderators reviewed the content with participants to ensure validity. Audio recordings were translated with some verbatim. Transcripts were reviewed independently by the investigator and open codes applied. Emerging themes were introduced into subsequent focus groups until saturation of topics was reached. Data were grouped according to themes using framework analysis and conceptualized into the key issues related to needs of the care givers Ethical approval to undertake this study was obtained from the Institution Ethical Committee of St. John's Medical College Bangalore. Research was carried out in two months period from March to May 2013.

The questions were included in the interview guide based on the findings of the literature review, experts' suggestions and experience of the investigator working with parents of the children with disabilities and the suggestions given by the parents of the children with disabilities. Moreover the interview guide was reviewed by the professionals in the similar field to ensure the face validity. Transcripts were prepared from the audio recordings and manually analyzed. The appropriate codes were assigned to different domains. The codes were then grouped together to create appropriate themes.

\section{Results}

Among the participants of this study four of them were illiterates and others had lower than or equal to a higher primary school education status. Two grandmothers and ten mothers were interviewed individually all other participated in focus group discussions. Their care receivers were the children in the age group of 1-12years having different disabilities. All these children were seen by the medical personnel and diagnosed for disabilities in the outpatient clinic at a centre for primary care level at Community Health Training Centre in a rural community.

\section{The needs identified from caregivers included:}

Emotional status, financial concerns, perceived family friends and community support, family burden understanding about the condition of the child, and suggestions to overcome the psycho social problems.

\section{Emotional challenges;}

The most difficult issues for emotional challenges for parents were the non progressive health status of the child. They carry the hope of progress in condition of the children with all kinds of efforts. Parents seek all kinds of treatment to support the child in order to improve the health status such as medical treatment and other 
alternative system of medicines. Many times parents get cheated by people for their false promises to get improvement in the health condition of the child.

As long as the child's basic needs are met no other things are caregiver's concern. Therefore care givers timely feed, clean, assist in toileting, changing dresses and management of medication for their disabled children. They have lot of fear in their day to day life. This fear is related to the perceived vulnerability of the child as he/she might not able to express his or her need, as illustrated in the following quotes expressed by different respondents during the discussions:

"What I perceived as a major concern is that, whenever child needs anything he cannot express, I'm always worried that this might be really a serious one.... because child cannot express what he need or express problems... As a mother it is my responsibility to provide all these. I should provide these. If I do not do all these I feel bad. Only mother can understands the feelings of their children easily. Who else can take over all these work? In the family also no one bothers."

"I worry a lot about my child's future. No one will take care of my child or he cannot take care of himself as well. I don't know who will be the first to go: he or me. If he goes first, I will not able to handle it...Therefore I will take him along with me before anything serious happens to him."

“...I'm afraid that she might get molested by others, as she grows into adolescence... I'm afraid that she will not have a ability to express what happened to her...since I cannot be with her all the time...I will have feeling of guilt."

The last quote belonged to a mother whose child aged 12 years with speech and hearing impairment. She was extremely concerned about the possibility of her child having the chances of abuse. She noted that this fear is related to the unpredictability of the people behaviour around them and social evils happening in the society.

In this study, the significant proportions of caretakers were home makers. Therefore, their primary concern was related to their perceived inability to continue providing care for their child until he/she becomes self-reliant.

\section{Stigma and ostracism towards disable individuals:}

This makes it difficult to find someone they can trust who would be willing and able to provide care for their child as a support hand to parents and grandmothers of the disable children as primary care givers.

This concern was illustrated in the following quotes:

"I always have the thought that if my child gets really sick, it would be best if she goes before me...because when she gets sick, I'm still able to take care of her... (sobbing).... But if I go before her she will be on her own when she gets sick... there will be no one there for her....I am very much worried.... if I go before her..."

"I am really worried about my daughter's future. We can spend money for her marriage. But who will marry her? Even if she get married she will get badly treated by her in-laws".

"I'm just worried that, when my daughter grows up, she requires different kinds of care which will continue for her life time. I don't know how long she will have someone paying for her necessary requirements...people hesitate to help her in our family other than me. I am very sure it will continue as long as she survives".

\section{Financial burden:}

Some of the subjects perceived, families from lower socio economic background find it very difficult to take disabled children to hospitals for therapies as well as for medications. Parents sacrifice their needs to fulfil the minimum needs of their disabled children. The roots of financial burden expressed by different participants during the interviews were as in the following verbatim. One of the participants expressed her financial burden by saying "Since my son is growing day by day..., I cannot carry him to get the exercise done at hospitals. I cannot take him by bus since he cannot move and I cannot lift him. I am unable to pay auto fare to take him by auto. I cannot go for any work, since all the time I have to be with him to look after. None of my family members are interested about him. They (children) support me with little money to spend for treatment of the disabled child.

The huge amount in the income of the families of the children goes to the medical treatment of the child. Some find it difficult to feed children with nutritious food. Due to dependency of the child for daily activities participants were not able to earn anything by using their skills to add up to their family income; neither have they completed their daily house hold work. They have to spend major time on their disabled child. Some of them become violent with their behaviour at the end of the day because of their continuous work without rest and have fatigue. 


\section{Family burden:}

Sometimes caregivers get blamed by their family members for not attending to other members requirements. It is quoted as follows; "The only work they do in the family is just looking after only the loved one (disable child). They are not thinking what others require in the family".

Some of the respondents shared their difficulties in attending any social functions. Basically they find it difficult to carry child to different places to attend functions. Other reasons for not attending functions were to avoid hundred and one questions asked by the people about their disabled child. I cannot face people with my child in big gatherings. Therefore I skip attending programmes.

About the daily rest most of subjects said they forgot the word of "rest". They do not even get time to think about taking rest. The reasons given for inability to take rest by the participants were they feel, they are the only members in the family providing care to their disable child and their disabled child also feel comfortable to receive care from them. Some of the respondents too mentioned they cope with their tiredness by making child happy and smile. Smiling face of their children makes them more energetic.

\section{Perceived Social support: \\ Support from family:}

Few of the subjects get supported from their family with financial support to care for the child. One of the subjects having a child with hearing impairment disclosed, her husband had given all the support to get all kinds of treatment. Child got treated with cochlear implantation for better hearing after spending twelve and half lakh rupees of money. After this treatment also child could hear a little bit but not clearly. He (husband) had been worrying a lot and developed hypertension. He lived very few days after he was diagnosed with hypertension. Within few days of the surgery of this child he collapsed and before reaching hospital he died. This subject claims the reason for death was the worry and anxiety about their child with hearing impairment. Another respondent mentioned about her husband's lack of support. He left her with one year old disabled child. He got married for second time and is living with second wife. The reason for leaving this particular subject was child's disability. She did not receive any help from him for the care of the child. Some of the care givers perceive that other than parents, siblings of the children also do not support in care.

Support from friends:

From this investigation it was found caregivers do not like to share their difficulties with anybody from outside the family. They have the fear of insult and sympathizing. Some of them did not want go out of the house and face people. It is illustrated in the following quotes. "If I share my difficulties outside the family they show sympathy which I do not want. But same people insult us by blaming us for having a disabled child. I blame and do not trust God. My expectation from people is not insult and blame. The families with disable children nothing else we require from them".

One of the mothers mentioned that her five children are married, among them two girls and three boys. After losing her husband four years she has not received any help from any of her children other than little money from youngest son to manage household expenditure and to fulfill the needs of the disabled child ( cerebral palsy). Married children did not want to stay with their disabled sibling. Most of the subjects did not have friends nor wanted to have friends. Reason they have given are; do not get matching interests, no time, do not want disclose anything with others due to the fear of insult.

Community support:

Subjects with lack of financial and social support perceive that very few people in the community have the interest to help disable people. According to them poor people who have faced similar problems can understand the difficulties of the families of the children with disabilities. Lack of support was perceived in availing welfare benefits from the government welfare benefits scheme. They feel only rich people in the village are supported by the village leaders to make it possible to avail welfare schemes. There is disparity shown by the elected members to make the resources to reach eligible beneficiaries.

\section{Social isolation:}

Some of the care givers experienced different kinds of discrimination. A 27year old mother referred to a 'stereotype' in the rural community where she lived as being conservative. She perceived that the people have discriminatory attitudes, especially among the people from higher socio economic background with no awareness about disabled children. This was intolerable and unacceptable. In the following words she gave in her interview about the nature of her people around in the community:

"In the village where I live there are mainly rich elderly people. They don't know about the causes; they are not educated. If someone suffers from disability they believe and say that it is due to past sin the family. People give the impression that we are bad people. They are really narrow-minded... They have never gone to school, so they don't know how the disability actually happens." 
Another respondent expressed her experience as isolated in public place as in market or buses. People express the feeling of discomfort by their body language. It is mentioned by some of the subjects, "People go away; show their unhappiness in their face to come and sit or stand closer to the people with disabilities. Children sometimes named with the type of disabilities they have. They are "kunta" to pyshically disabled, "pedda" to mentally challenged. But they felt it is been practiced from many years in the community. Now cannot do anything to stop these issues in the society.

\section{Suggestions to meet the needs:}

Subjects perceive there is no way to reduce their problem. In both focus group discussions subjects felt they were emotionally relaxed during the discussion with other members. They felt there won't be any harm in sharing their problems with people who have similar problems. Many of the care givers who got interviewed felt their problem will be solved only the day when they end their life. They could not think beyond this for that moment during the individual interviews. Providing them knowledge on appropriate way of tapping the resources is one of the suggestions given by the study group.

\section{Implications:}

The needs and suggestions of the target groups to address their psycho social needs were different types of services. Such as creation of awareness session with family and community about the causes, treatment, welfare services available, regular group meeting with parents to improve social support, regular communication (counseling), and disclosure of the prognosis of the problem. Thus, the information gained can be used to plan the intervention program for the care givers and their loved ones with disabilities to improve their quality of life.

\section{Discussion}

These findings indicates care givers are at greater risk of psychological distress, much of the data continue to point to a need for psychosocial adjustment and support. Understanding the psychosocial needs among care givers of the children with disabilities is critical for improving their mental health and quality of life. Health problems are poorly understood by the care givers. Improving the psycho social health of the care givers can have good impact on their own health as well as improve the quality of the life of the children.

The data provided in this study support previous research on the need for psychological assessment and interventions for care givers of the children with disabilities. Despite the variability in their demographic and background social variables which may influence their primary psychosocial needs when dealing with care givers of the children with disabilities, the current research identifies many important psychosocial concerns common to care givers population. These concerns and challenges shared among these population include marital separation, emotional disturbances, social discrimination, treatment affordability, impact of the illness and child's future and financial constraints. Certain issues that emerged as important themes specific to this population include, future child guardianship and rehabilitation, mobility of the children, misinterpretation of the nonverbal cues in community, treatment availability and difficulties in accessing services due the transportation difficulty.

\section{Conclusion}

From the results, many of the matters can be alleviated by providing correct information to caregivers. This study supports the importance of such communication with families. The areas that can be targeted for support include strategies to cope with their psycho social needs, awareness on intervention, life skills building, and empowerment by mobilizing the parent support group. Many of these cannot be addressed by health care providers alone. Social workers, counselors, Peer group support and partnership with various organizations are some of the potential solutions. It gives an idea to have private sessions with health care providers, where care givers innermost concerns can be identified and properly addressed. This study points to the unique needs of care givers of the children with disabilities and emphasize the need for psychosocial intervention and support in a wider perspective.

\section{References}

[1]. Marcia A. Cohen, A book on Impact of a Handicapped Child on the Family, Haven Teachers Institute 2014

[2]. World Health Organization. International Classification Functioning, Disability and Health (ICF). Geneva: World Health Organization, 2002.

[3]. Patel S. An Empirical Study of Causes of Disability in India. Internet Journal of Epidemiology, 2009; Volume 6 Number available @.http://www.disabilityindia.com/html/facts.html.

[4]. David Jenkins, Ph.D. A HANDBOOK OF BEHAVIORAL CHANGE Scientific and Technical Publication 2003 No. 590 PAN AMERICAN HEALTH ORGANIZATION Pan American Sanitary Bureau, Washington, D.C. 20037, U.S.A ISBN 9275 11590).

[5]. LUCYNA M. LACH 1, DAFNA E. KOHEN 2. The health and psychosocial functioning of caregivers of children with, neuro developmental disorders, Disability and Rehabilitation, 2009; 31(8): 607-618) 